\title{
Experimental Study of An Enhanced Prototype of Ballast Water Treatment Using Filtration of Crumb Rubber and UV Radiation
}

\author{
Trika Pitana ${ }^{1, a, *}$, Halimah Puspitasari ${ }^{1, b}$, and Maya Shovitri ${ }^{2, c}$ \\ ${ }^{1}$ Department of Marine Engineering, Institut Teknologi Sepuluh Nopember Surabaya, Surabaya, \\ Indonesia \\ ${ }^{2}$ Department of Biology, Institut Teknologi Sepuluh Nopember, Surabaya, Indonesia \\ a.trika@its.ac.id,b.halimahp017@gmail.com,c.maya@bio.its.ac.id \\ *corresponding author
}

Keywords: Ballast Water Treatment; Crumb Rubber; UV Radiation

Abstract: To maintain the balance of the ship from trim or rolling, especially when the ship is loading or unloading, it is necessary to fill and discharge ballast water in the tanks, so that is can keep the ship's weight as low as possible and maintain the position of the ship always in the event of the keel. Ballast water used is needed a processing process if it will be thrown back to the sea. Due to the IMO described the regulation of ballast water, it shall be treated before the sea water is discharge to the sea for protected from microorganism that can damage the surrounding environment. The one of the ways to inactivate the microorganism is using filtration of crumb rubber and UV radiation. The used method in this research is scalling up the UV reactor from the first prototype. In this research, it is known the addition of effective and efficient flow rate with the capacity of $10 \mathrm{Lpm}, 30$ $\mathrm{Lpm}, 50 \mathrm{Lpm}$ and $70 \mathrm{Lpm}$. Final goal of this research is to validate the information of microorganism contain from the first prototype and the scalling up prototype. To calculate the microbial content in the water samples is using Total Plate Count (TPC) method with Eosin Methylene Blue (EMB) as bacteria growing media and Aquades with salinity as a medium of diluent. The most effective and efficient flow rate and dose of UV in inactivating microbial content is $10 \mathrm{Lpm}$ and the UV dose is 120 watts. The results of this research have the same consistency from the previous one and prove that scalling up prototype can reduce the amount of microbial content. It is hoped that this research can be one way to reduce the results of microbial content in the ballast water in accordance with IMO standardization.

\section{Introduction}

The ship is a widely used to transportation, especially in areas that have very large waters. One things to note in the safety of ships is a water ballast system that serves to maintain the balance of the ship in case of trim or rolling especially when the ship will loading or unloading. This ballast system works by filling and discharge of sea water to ballast tank or from ballast tank to overboard. The function of ballast system is to keep the center of the ship as low as possible and maintain the 
position of the ship is always in even keel. In addition to the positive impacts of ballast system, this system has a negative impact of microorganisms contained in the water or in ballast tank. So that when this water is discharge in any place, and if the environment supports these microorganisms to live, then this microorganism will cause the extinction of the native species.

To overcome with pollution caused by the ballast water, in 2004 IMO issued a regulation on ballast water treatment management written in IMO ballast water management convention. Therefore there are several ways that can be used to reduce the amount of microbial content, such as, using crumb rubber filtration, carbon active filtration, and combine between crumb rubber filtration and UV radiation.

The use of ballast water treatment system using crumb rubber [1] filtration and UV radiation has been applied before and based on this research result is $99 \%$ microbial in sea water sample is inactivated by used this prototype with maximum flow rate is $20 \mathrm{Lpm}$ and minimum UV dosage equal to $7.10 \mathrm{~mW} / \mathrm{cm} 2$. In this experiment it is said that the surface area of crumb rubber filter applied is $10 \mathrm{~cm} \times 10 \mathrm{~cm}$ and produce carbon filter more effective and efficient in filtering microbial content. In this study can be analyzed that there are indications of over capacity in this prototype [2][3][4].

To follow up on the research that has been done before, the experimental method was developed to make the water ballast treatment system using rubber filtration of crumb and UV radiation with a large size that is scalling up twice from the first prototype. The surface area used in this experiment is $0.5 \mathrm{~cm} \times 0.5 \mathrm{~cm}$ and uses the variation of flow rate is $10 \mathrm{Lpm}, 30 \mathrm{Lpm}, 50 \mathrm{Lpm}$ and $70 \mathrm{Lpm}$. For the use of UV doses, the use is increased to 30 watts, 60 watts, 90 watts and 120 watts. To analyze the microbial content in the water sample is using Total Plate Count method (TPC) which uses aquades with a salitiy same as water sample as a diluent and uses Eosin Methylene Blue (EMB) as a specific medium for bacterial growth. Scalling up the prototype is done to validate the results of previous research. If the test results are consistent, it can be said that the design of the prototype is made work effectively and efficiently in producing standardized ballast treatment by IMO Ballast Water Management Convention.

\section{Methodology}

\subsection{Calculate Salinity of Seawater}

To determine of salt content to be added to the aquades to create a diluent medium with the same salinity as sea water, a salinity rate is required. Meanwhile, to determine the salinity of Kenjeran Beach is using a refractometer and produce salinity of $250 / 00$. The formula for knowing the salt content contained in seawater is:

$$
\begin{aligned}
& \mathrm{S}(0 / 00)=0.03+1.805 \mathrm{Cl} \\
& \mathrm{m}=(\mathrm{gr} / \mathrm{Mr}) \times(1000 / \mathrm{P})
\end{aligned}
$$

\subsection{Analyse Microbial Content Using Total Plate Count (TPC) Method}

To determine the amount of microbial content in the water sample, the used method is Total Plate Count (TPC) which uses Eosin Methylene Blue (EMB) as a specific medium of bacterial growth and Aquades with salinity as a diluent. The principle of the TPC method is to grow cells of living microorganisms on the media so that microorganisms will multiply and form colonies that can be seen directly and counted with the eye without using a microscope. The Stages of TPC method can be seen in Figure 1. 


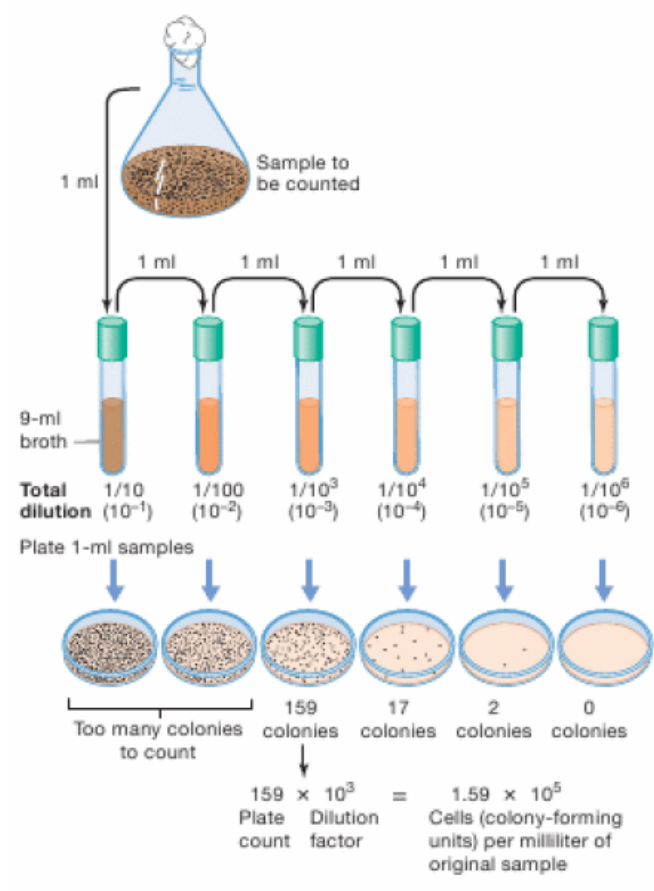

Figure 1: Diluent Technic of Water Samples

Based on Figure 1 above, the dilution step starts from making a $10 \mathrm{ml}$ sample solution (mix 1 $\mathrm{ml}$ water sample with $9 \mathrm{ml}$ of aquades with salinity). From the solution will be mixed and will be taken back as much as $1 \mathrm{ml}$ and put into $9 \mathrm{ml}$ aquades with salinity on the second tube to obtain dilution 10-2. From the 10-2 dilution it will be recovered as much as $1 \mathrm{ml}$ and inserted into a third reaction tube containing $9 \mathrm{ml}$ of aquades with salinity solution and obtained 10-3 dilution.

After dilution has been done, then the next step is carried out bacteria that contain a cup that already contains EMB and keep it for a day to determine the development of bacteria. After that will be calculated from the number of bacterial colonies that grow on the cup. The calculation of the amount of microbes contained in the cup can be calculated using a colony counter.

There are some things that must be considered in calculating for this method, which are:

1. The selected and calculated plates the one which has number of colonies between 25 to 250 colonies.

2. Some colonies that merge into one are a large collection of collonies where the number of colonies is in doubt, can be counted as a colony.

3. A row or chain of colonies that looks like a thick line is counted as a colony.

\section{Result and Discussion}

\subsection{Design Prototype of Ballast Water Treatment}

Figure 2 shows a process diagram of a prototype ballast water system where sea water from Kenjeran Beach and still contains many microorganisms will be accommodated in tank 1 and will be pumped at different flow rate. The flow rate of sea water will be regulated by the valve and will be monitored using a flowmeter. Once the seawater is pumped, then the sea water will go into filter 1 to filtered the microbial content. After that sea water will re-enter into filter 2 to do a second filtration of microbial content. In this experiment will use 2 filters that use crumb rubber and use carbon active filter. 


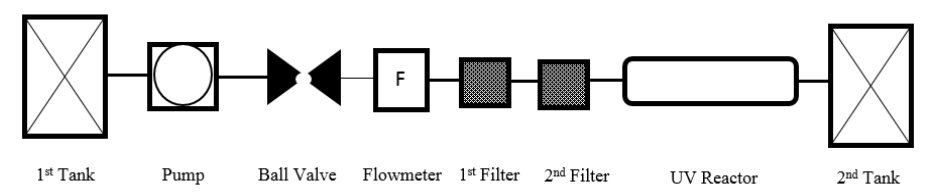

Figure 2: Diagram Process of Prototype Ballast Water Treatment

Furthermore, from the filtration results, the sea water will enter the UV reactor to conduct the inactivation of the microbe. Inside the UV reactor will also be set the dose of UV light irradiation. Because the prototype uses 4 UV lamps with 30 watts of power, the maximum of UV lamp irradiation dose is 120 watts. After the inactivation of microorganisms, the processed sea water will enter the tank number 2 to test the content of microorganisms contained in the sea water that has been done processing.

\subsection{Salinity Calculation}

Salinity is the sum of all salts in units of grams per kilogram of sea water. Therefore, the amount of salinity is done by reviewing the most important component of chloride $(\mathrm{Cl})$. The factors are affecting salinity include :

1. Evaporation, the greater of sea water evaporation, the salinity is high and vice versa in the low sea level evaporation rate, then the area has low salinity.

2. Rainfall, the greater of rainfall in a sea area then the salinity of the sea water will be low and otherwise the lower rainfall will decrease the salinity will be higher.

To measure the salinity of the Kenjeran Beach, then the required salinity water of the Sea of Kenjeran by using a measuring instrument that is refractometer where the results of the measurement of salinity can be seen in Table 1 .

Table 1: Salinity Measurement

\begin{tabular}{|c|c|c|}
\hline No & Location & Salinity Value \\
\hline 1 & Surface Water & $25 \%$ \\
\hline 2 & Bottom Surface & $25 \%$ \\
\hline
\end{tabular}

Based on the results already obtained on taking salinity data on the surface of waters and bottom waters shows a salinity of $25 \mathrm{o} / \mathrm{oo}$. The coastal areas have salinity ranges from $32-34 \mathrm{o} / \mathrm{oo}$, in open sea salinity ranges from 33 to $37 \mathrm{o} / \mathrm{oo}$ with an average of $35 \mathrm{o} / \mathrm{oo}$ [5]. From salinity measurement results can be seen the difference of salinity value in general is still $<32 \mathrm{o} / \mathrm{oo}$, then the waters are still influenced by the beach. It is suspected that the influence of the land as a mixture with fresh water carried by the river flow. This salinity is still within the limits of the normal salinity of coastal water and mixed water [6]. 


\subsection{Analysis of Microbial Content Using Filtration of Crumb Rubber}

Based on Table 2 dan Figure 3, discussion started with observing the difference of flow rate in accordance with the total amount of microbes in each sample. From that data, it can be seen that the early condition with 30 watts of UV dosage, and flow rate as much as $10 \mathrm{Lpm}$, total amount of microbes are $7 \times 104 \mathrm{CFU}$, and with the flow rate of $30 \mathrm{Lpm}$ total amount of microbes become $40 \mathrm{x}$ $104 \mathrm{CFU}$. But on $50 \mathrm{Lpm}$ of flow rate, the total amount of microbes decreases to $6 \times 104 \mathrm{CFU}$ and on $70 \mathrm{Lpm}$, total amount of microbes increases again to $27 \times 104 \mathrm{CFU}$.

Table 2: Microbial Content Using Crumb Rubber (CFU)

\begin{tabular}{ccccc}
\hline & \multicolumn{4}{c}{$\mathbf{1 0}^{\mathbf{4}}$} \\
\hline $\begin{array}{c}\text { UV Dosage } \\
\text { (Watt) }\end{array}$ & $\mathbf{1 0}$ & $\mathbf{3 0}$ & $\mathbf{5 0}$ & $\mathbf{7 0}$ \\
\cline { 2 - 5 } 30 Watt & 7 & 40 & 6 & 27 \\
\hline 60 Watt & 5 & 21 & 1 & 12 \\
\hline 90 Watt & 2 & 4 & 77 & 8 \\
\hline 120 Watt & 1 & 3 & 132 & 5 \\
\hline
\end{tabular}

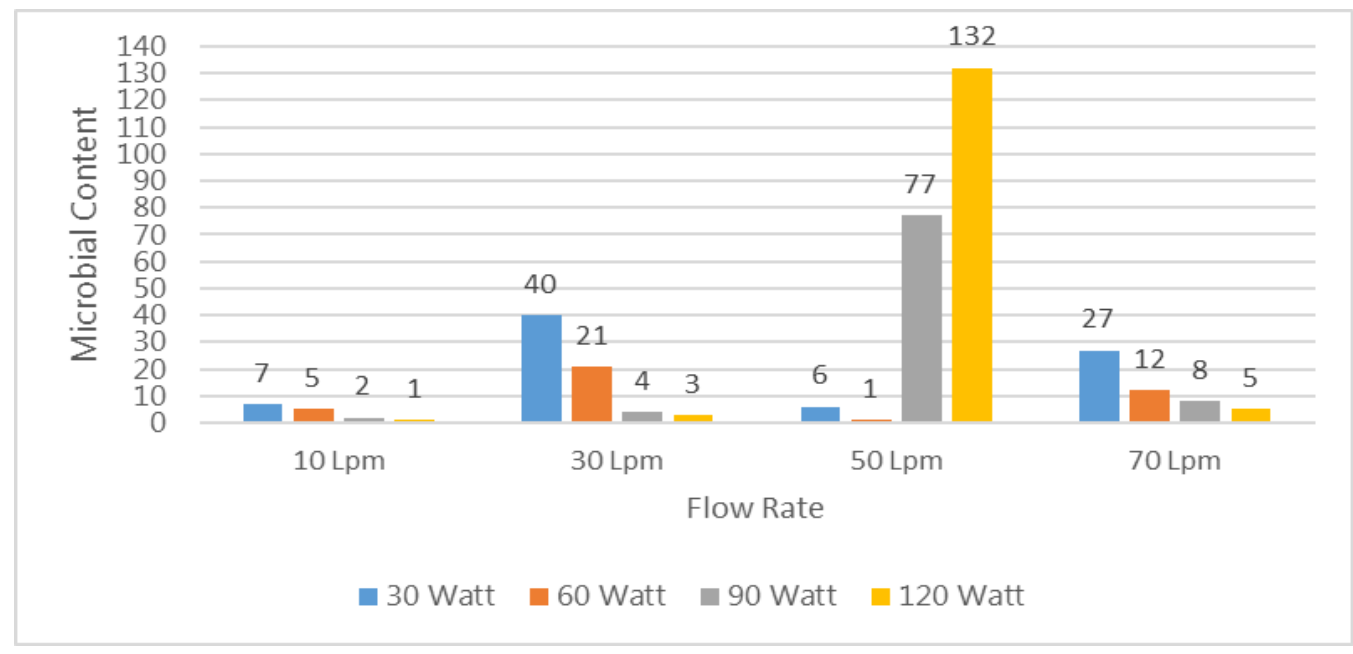

Figure 3: TPC Result Using Filtration of Crumb Rubber

Afterwards, on the experiment of using 60 watt of UV and with $10 \mathrm{Lpm}$ of flow rate, the total amount of microbes on the water sample is $5 \times 104 \mathrm{CFU}$, and on $30 \mathrm{Lpm}$ total amount of microbes increases to $21 \times 104 \mathrm{CFU}$. Next, on $50 \mathrm{Lpm}$, the total amount of microbes become $104 \mathrm{CFU}$ and last, on $70 \mathrm{Lpm}$, total microbes increase again to $12 \times 104 \mathrm{CFU}$.

Based on the results shown, it can be seen that the greater the flow rate combined with a constant dosage of UV ( 30 watt or 60 watt) could affects on the total amount of microbes on each sample. The greater the flow rate, the greater amount of microbes that appear. This happens due to the greater flow rate given to the sample, therefore the chance of microbes absorbing the UV light is less. The faster the flow rate, the time of UV irradiation will be lesser, that is why the microbes that went through the UV reactor will still be alive before it could be inactivated.

Second discussion is observing the impact of UV dosage on the amount of microbes of each sample. This experiment begins with observing on $10 \mathrm{Lpm} 30$ watts of UV light, the result is $7 \mathrm{x}$ $104 \mathrm{CFU}$ of microbes, then after adding UV dosage to 60 watt, 90 watt and after that 120 watt, result shows that there are reduction of microbes which is $5 \times 104$ to $2 \times 104$ and to 104 . 
When the experiment on $30 \mathrm{Lpm}$, the same pattern was seen on the result, which is the greater the UV dosage (with the same flow rate) the less microbes survive on each sample.

From the 2 discussions, it is concluded that the addition of flow rate and UV dosage that is used on the experiments will affects on the total amount of microbes in each sample. The faster the flow rate combined with a constant dosage of UV, the more microbes there are on each sample. But on the contrary, the higher dosage of UV used in the same flow rate, the lesser microbes survived on each sample.

But, on $50 \mathrm{Lpm}$, there is a inconsistency because of contaminant. The sources of contamination can be caused by various things, among others, during the process of sampling, storage of samples, as well as at the time of conducting test analysis [7].

\subsection{Analysis of Microbial Content Using Filtration of Carbon Active}

Carbon filter is commonly used by Indonesian citizen as a filter to filtrate water from microbes. This filter uses activated carbon that acts to absorb particles or microbes in the water. On this research, performance of filter using activated carbon is compared to filter using crumb rubber. To view the results of the experiment, check Table 3 and Figure 4.

Table 3: Microbial Content Using Carbon Active (CFU)

\begin{tabular}{|c|c|c|c|c|}
\hline \multicolumn{5}{|c|}{$10^{4}$} \\
\hline \multirow{2}{*}{ UV Dosage (Watt) } & \multicolumn{5}{|c|}{ Flow rate (Lpm) } \\
\cline { 2 - 5 } & 10 & 30 & 50 & 70 \\
\hline 30 Watt & 30 & 16 & 14 & 3 \\
\hline 60 Watt & 19 & 3 & 7 & 19 \\
\hline 90 Watt & 4 & 1 & 5 & 0 \\
\hline 120 Watt & 2 & 1 & 3 & 7 \\
\hline
\end{tabular}

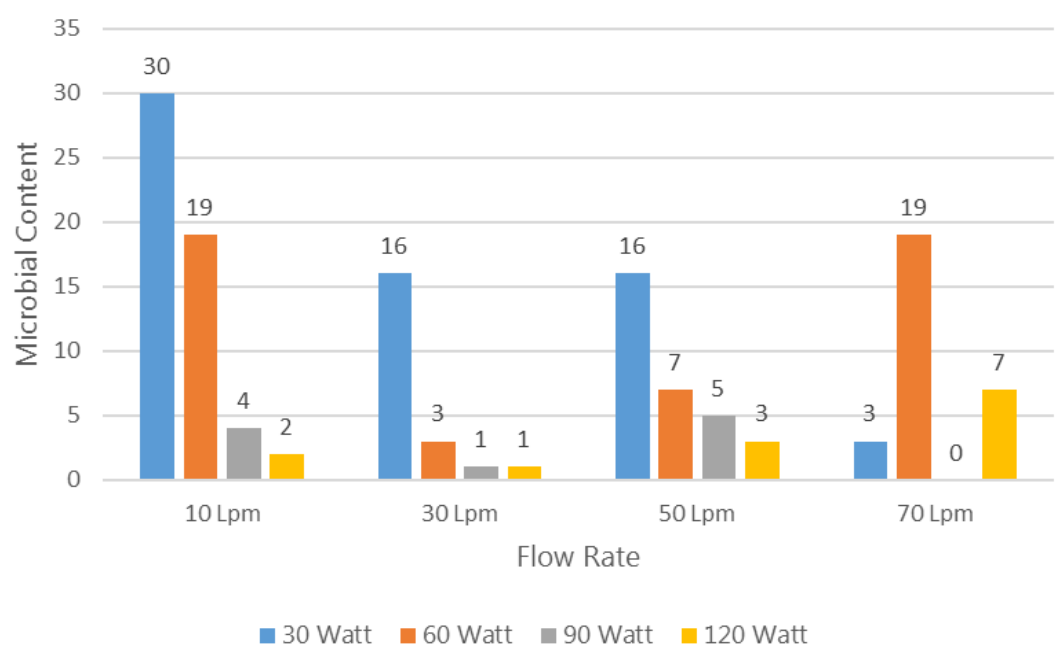

Figure 4: TPC Result Using Filtration of Carbon Active

Discussion on this observation also begins by observing the difference in flow rate to the amount of microbial content contained in the sample water. As with crumb rubber filters, the higher the flow rate given will get higher the amount of microbial content it contains. But on the experiments that have been done, this application occurs when the use of UV doses of 60 watts and 120 watts. At the time of UV dose of 30 watts and 90 watts, the number of microbes decreased. 
From the above data, the difference of UV dose application to the flow rate affects the amount of microbial content. The difference of this application can be affected by the original nature of the activated carbon. The adsorption properties of activated carbon are strongly influenced by various factors such as pore structure, activation method, raw material and carbon surface chemical properties.

The second discussion is to observe the effect of UV dosage on the amount of microbial content contained in the sample water. As in testing using crumb rubber filters, this observation shows that the greater the UV dosage given the smaller the amount of microbial content. It can be seen in Figure 5 on the test using $10 \mathrm{Lpm}$ flow rate with UV dose of 30 watts, the microbial content is $30 \mathrm{x}$ $104 \mathrm{CFU}$, then with the addition of UV dosages of 60 watts, 90 watts and 120 watts respectively, the number of microbial contents in sequence is $19 \times 104 \mathrm{CFU}, 4 \times 104 \mathrm{CFU}$ and $2 \times 104 \mathrm{CFU}$.

In the test observed using flow rates of $30 \mathrm{Lpm}$ and $50 \mathrm{Lpm}$, it is seen that the results of this test have the same pattern with the previous test that the greater UV doses given the smaller the amount of microbial content contained in the sample water.

\subsection{Comparison of Crumb Rubber and Active Carbon}

From the results of previous discussion, it is seen that at dilution 104 crumb rubber more effective and efficient in filtering microbial content in water samples. To know the consistency of the effectiveness and efficiency of crumb rubber filters, it is necessary to review the results of filtration of crumb rubber filters and carbon filters on the dilution of 105 and 106 . This is to validity and determine the most effective and efficient filter types to filter microbial content.

Table 4 and Table 5 show quantitative data on microbial content due to the influence of crumb rubber filters and carbon filters during the dilution of stages 105 and 106. As for Figure 5 and Figure 6 shows the comparison of crumb rubber filters and carbon filters to the amount of microbial dissolution stage 105 and 106 at $10 \mathrm{Lpm}$. Using flow rate at $10 \mathrm{Lpm}$ because in the previous results it can be seen that the most effective flow rate in filtering and inactivating the microbial content amount is at a flow rate of $10 \mathrm{Lpm}$.

Table 4: Effect Of Filter By Tpc Result 105 Dilution

\begin{tabular}{|c|c|c|c|c|c|c|c|c|}
\hline \multirow{3}{*}{ UV Dosage (Watt) } & \multicolumn{9}{|c|}{$10^{5}$} \\
\cline { 2 - 10 } & \multicolumn{9}{|c|}{ Clow Rate (Lpm) } \\
\cline { 2 - 10 } & \multicolumn{9}{|c|}{ Crumb Rubber } & \multicolumn{4}{c|}{ Carbon } \\
\cline { 2 - 9 } & 10 & 30 & 50 & 70 & 10 & 30 & 50 & 70 \\
\hline 30 Watt & 7 & 12 & 4 & 12 & 13 & 4 & 2 & 4 \\
\hline 60 Watt & 7 & 8 & 0 & 3 & 15 & 2 & 5 & 1 \\
\hline 90 Watt & 6 & 5 & 30 & 3 & 3 & 1 & 1 & 2 \\
\hline 120 Watt & 1 & 4 & 12 & 2 & 1 & 2 & 3 & 1 \\
\hline
\end{tabular}




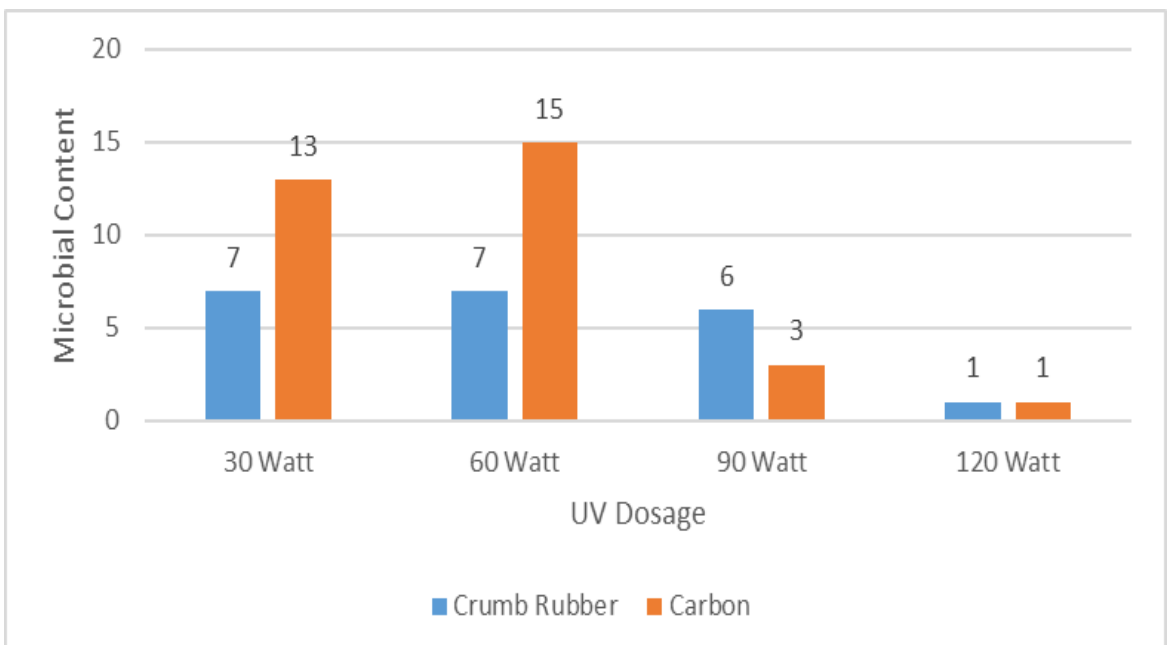

Figure 5: Comparison of Crunb Rubber and Carbon on $10^{5}$ Dilution with flow Rate $10 \mathrm{Lpm}$

Table 5: Effect of Filter By Tpc Result Of 106 Dilution (CFU)

\begin{tabular}{|c|c|c|c|c|c|c|c|c|}
\hline & \multicolumn{9}{|c|}{$10^{6}$} \\
\cline { 2 - 9 } & \multicolumn{9}{|c|}{ Flow Rate (Lpm) } \\
\cline { 2 - 9 } UV Dosage (Watt) & \multicolumn{9}{|c|}{ Crumb Rubber } & \multicolumn{5}{c|}{ Carbon } \\
\cline { 2 - 9 } & 10 & 30 & 50 & 70 & 10 & 30 & 50 & 70 \\
\hline 30 Watt & 10 & 0 & 1 & 14 & 23 & 0 & 1 & 2 \\
\hline 60 Watt & 7 & 2 & 1 & 2 & 6 & 2 & 7 & 0 \\
\hline 90 Watt & 1 & 0 & 9 & 1 & 2 & 11 & 1 & 1 \\
\hline 120 Watt & 0 & 1 & 7 & 1 & 1 & 1 & 0 & 1 \\
\hline
\end{tabular}

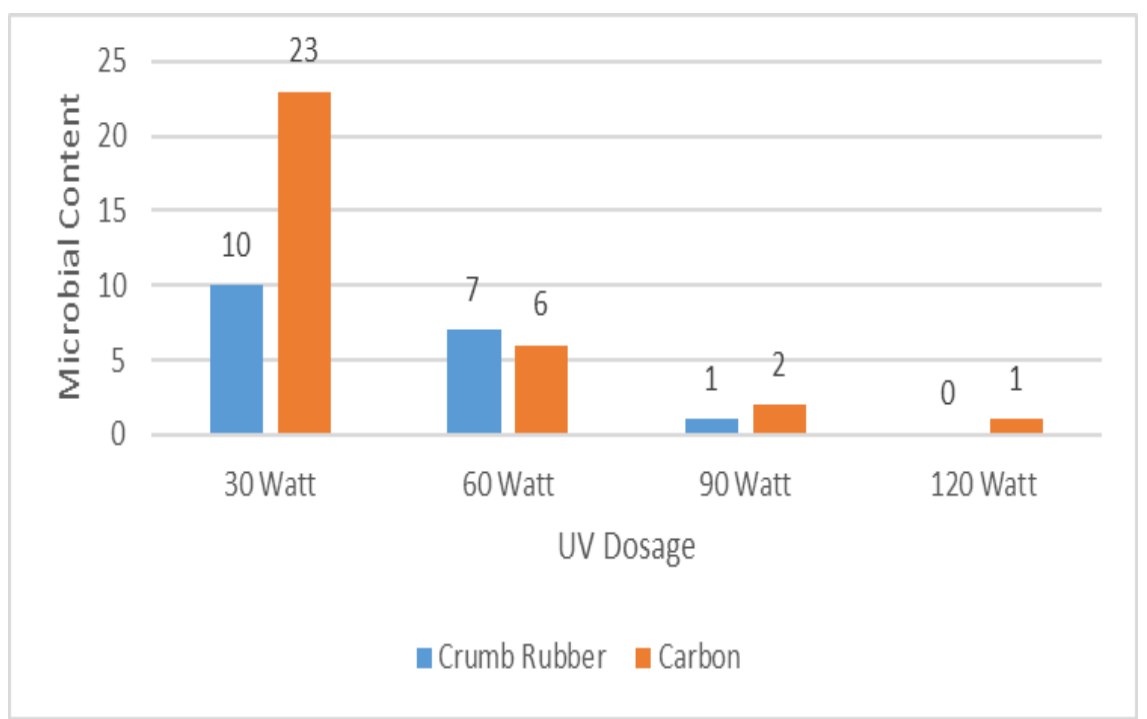

Figure 6: Comparison of Crumb Rubber and Carbon on 106 Dilution with flow Rate 10 Lpm

Overall, it is seen that at dilution 105 and 106 crumb rubber filters are more effective and efficient in filtering the microbial content which can be reviewed based on flow rates and given UV doses. In terms of economical, crumb rubber filters are cheaper than carbon filters. 


\subsection{Comparison of Previous Experiments with the Scalling Up}

Some ballast water treatment applications to be able to inactivate microbes have been done, one of them using UV radiation and filtration usage. To validate the results of a test on the reply processing tool required a way that is by scalling up. By using scalling up, it is expected that the results obtained will be close with the previous results. In the reply processor, which needs attention when scaling up is the magnification scale of the filtration system and the UV dosage [8].

The discussion begins by comparing the first prototype results with the scaling up prototype. Based on previous result, when using sterile seawater as a diluent with the same flow rate of 10 Lpm and UV dose of 30 watts and 60 watts using carbon filter $13 \times 104$ CFU and 107 CFU of microbial content. Then the amount of microbial content when using carbon filter with $10 \mathrm{Lpm}$ flow rate and UV dose of 30 watts and 60 watts is $15 \times 104$ CFU and 0 [1].

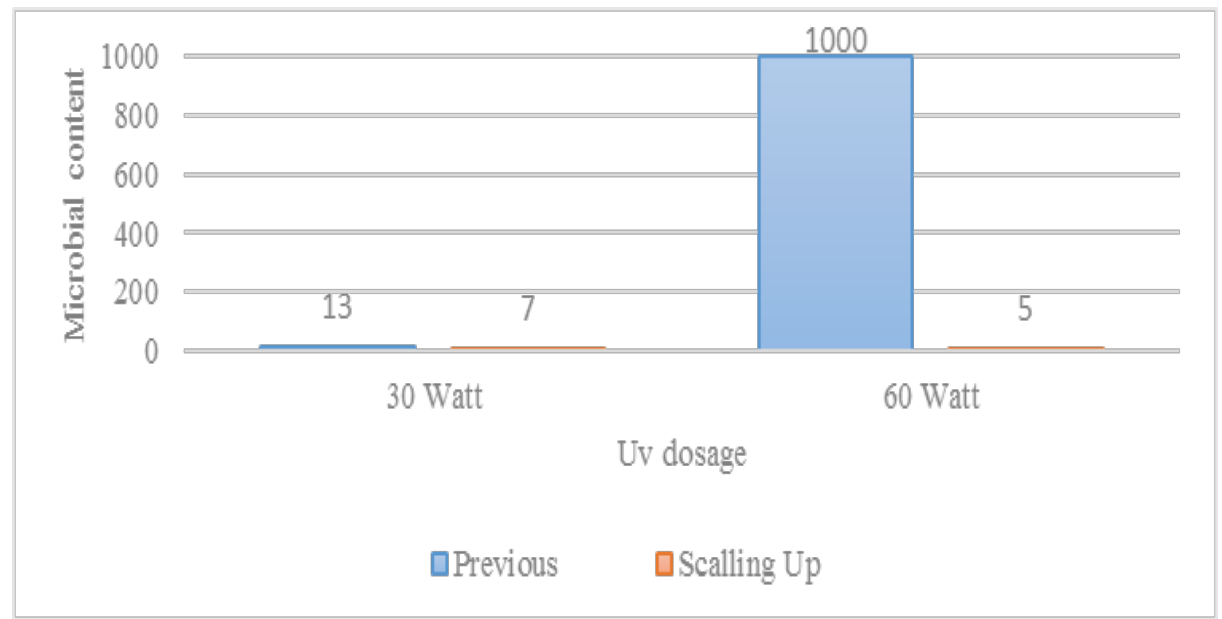

Figure 7: Performance Comparison of Previous Prototype with the Scalling Up Using Crumb Rubber

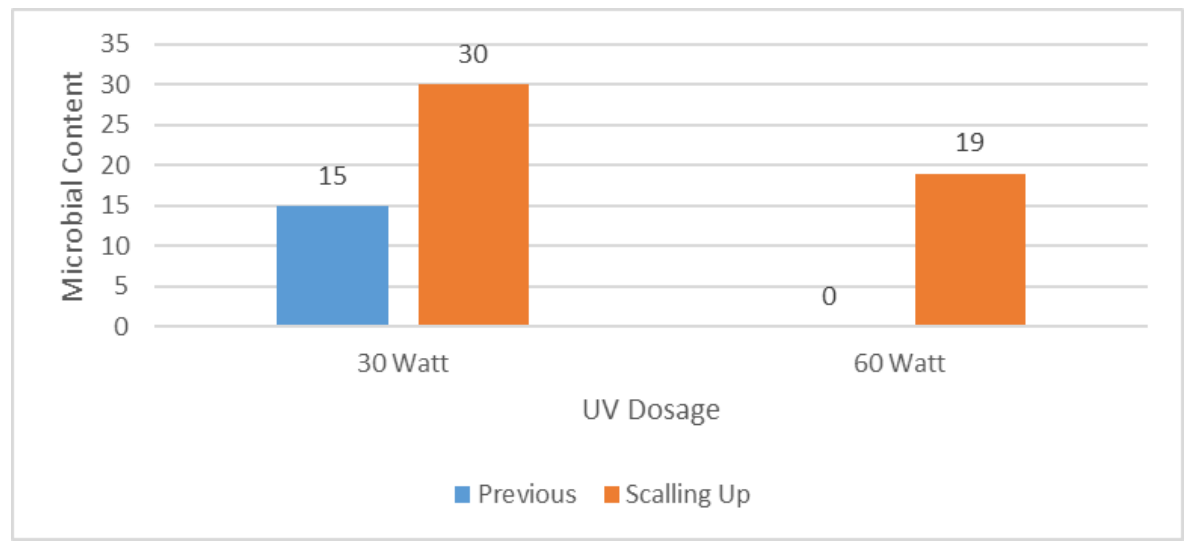

Figure 8: Performance Comparison of Previous Prototype with the Scalling Up Using Carbon Active

From the above data, can be seen at the time of using crumb rubber filter, the amount of microbial content decreased at the time of scalling up. However, when using carbon filters, the amount of content is still greater than when using the previous prototype. 
The second discussion is to observe the results of previous prototype testing using sterile aquades as a diluent. Based on data obtained from the previous test, the amount of microbial content contained in the sample water was 0 for a $10 \mathrm{Lpm}$ flow rate with 30 watt UV doses and 60 watts at the time of use of crumb rubber filters and carbon filters. However, at the time of testing at $10 \mathrm{lpm}$ flow rate and 30 watt UV doses using crumb rubber filter, the amount of microbial content obtained was $10 \mathrm{CFU}$.

The result of the previous produce 0 can be caused by the occurrence of hemolysis in the microbe before testing. This hemolysis may occur due to lower salinity levels compared to sea water samples, the microbes will not live and are dead first so that the results of this test can not be said to be valid.

From the result of data comparison above, it can be concluded that scalling up prototype can inactivate microbial content in ballast water. Based on the previous test results, it is found that carbon filters work more effectively than crumb rubber filters. However, in the study using this scalling up, the results obtained are crumb rubber filters are more effective and efficient in filtering microbial than carbon filters.

This difference may occur due to differences in the area of crumb rubber smaller than in the previous test. With the smaller area created, the more effective the crumb rubber in filtering microbial content.

\section{Conclusions}

Based on experiment above, we can conclude that the ballast water treatment prototype used can perform the most effective microbial inactivation on seawater samples when using a $10 \mathrm{Lpm}$ flow rate and maximum UV dose of 120 watts.

The results using this prototype resulted in the crumb rubber filter more effective and efficient in filtering the microbial content in the water samples. With the use of scalling up on this prototype it can be seen that it can reduce the amount of microbial content in previous test results when using crumb rubber filters. With this prototype, it's validating that when using a sterile Aquades as a diluent, the microbial content in the water samples was hemolytic due to the difference salinity so that the results of the previous test were unusable or invalid.

\section{References}

[1] Tang. Z, Butkus. M.A, Xie. Y.F. “Crumb Rubber Filtration: A Potential Technology for Ballast Water Treatnent Mar. Environ” Res. 61, 410-423.

[2] T. Pitana, M. Shovitri, and H.N. Fauzi.. "Analysis of Microbial Inactivation Performance on Ballast Water Treatment System Prototipe Using Combination of Active Carbon and UV Radiation”. World Conference on Applied Science Engineering and Technology, 17,10. 2017

[3] T. Pitana, M. Shovitri, and H.N. Fauzi.. "Preliminary Study Of The Using of Crumb Rubber Filtration and UV Radiation As Medium For Treating Ship's Ballast Water”. International Conference on Marine Technology, 2017.

[4] T. Pitana, M. Shovitri, and H.N. Fauzi.. "Preliminary Study Of The Development Of Ballast Water Treatment Prototipe Using Filtration and UV Radiation Methode”. International Journal of Marine Engineering Innovation and Research, 2017.

[5] Jemmy Souhoka2, Simon I Patty. "Sulawesi utara1 Hydrology Monitoring In Conjunction With The Condition Of Coral Reefs In The Waters of Talise Island, North Sulawesi”. Jurnal Ilmiah Platax Vol. 1:(3), ISSN: 2302-3589. Mei (2013).

[6] Simon I Patty. "Distribution Temperature, Salinity And Dissolved Oxygen In Waters Kema, North Sulawesi". Jurnal Ilmiah Platax Vol. 1:(3), ISSN: 2302-3589. Mei (2013).

[7] R.S. Hadioetomo “Basic Microbiology in Practice, Technique and Procedure Basic Laboratory”. Jakarta: PT. Gramedia Pustaka Utama. 1993

[8] J. Cosman, J. Fraser, G. Latimer and J.G. Fraser. "Validation Protocol for Performance Testing and Scaling Ballast Water Treatment Systems Employing UV Disinfection and Filtration”. London, Ontario Canada 